\title{
Development of GC-MS/MS Method for Simultaneous Estimation of Four Nitrosoamine Genotoxic Impurities in Valsartan
}

\author{
(D) Sambasiva Rao TUMMALA, iD Krishnamanjari Pawar AMGOTH* \\ Andhra University, College of Pharmaceutical Sciences, Department of Pharmaceutical Analysis, Andhra Pradesh, India
}

\begin{abstract}
Objectives: Recently, $\mathrm{N}$-nitrosamines were unexpectedly detected in valsartan and other generic sartan products. Taking into this account, we developed a sensitive and stable multiple reaction monitoring mode-based "gas chromatography-tandem mass spectrometry (GC-MS/MS)" approach for the quantification of "four $N$-nitrosamines" in valsartan, especially, $N$-nitrosodiisopropylamine, $N$-nitroso ethyl isopropylamine, $\mathrm{N}$-nitrosodiethylamine, and $\mathrm{N}$-nitrosodimethylamine.

Materials and Methods: GC and MS conditions were optimized with specificity, sensitivity, linearity, precision, and accuracy of the parameters. The approach was validated as per the "International Council for Harmonization" recommendations.

Results: The identification limits and limits of quantification of $\mathrm{N}$-nitrosamines in valsartan varied between 0.02 and 0.03 ppm, and $0.06-0.09$ ppm, respectively. The obtained values were satisfactory with limits established by the United States Food and Drug Administration for sensitivity requirements. The regression coefficients greater than 0.999 for four $N$-nitrosamines in the calibration curve demonstrated the strong linearity of the process. The retrievals of " $N$-nitrosamines" in valsartan between $91.9-122.7 \%$. For the intra-day and inter-day accuracy studies, the (relative standard deviation) was less than $9.15 \%$.

Conclusion: The proposed approach has rapid analysis capability, high precision, accuracy, and good sensitivity, which give a reliable approach for $\mathrm{N}$-nitrosamines quality control in valsartan.
\end{abstract}

Key words: GC-MS/MS, valsartan, $N$-nitrosamine, genotoxic impurity

\section{INTRODUCTION}

In the production process of the "active pharmaceutical ingredients (APIs)", impurities are incorporated through various sources, like catalysts, solvents, reagents, intermediates, starting materials, and by-products. Compared to other impurities, genotoxic impurities (GTIs) are of a special kind that could inspire mutations at the genetic level, which lead to chromosomal breakage and rearrangements, and even present in low concentrations have increased the risk of cancer. Considering into account the toxic effects of GTIs the international regulatory bodies had set an exposure limit thresholds for GTIs, specifically, $1.5 \mu \mathrm{g} /$ day for long-run therapy with greater thresholds of clinical shorter intervals. As these
GTIs are present in very low concentrations, the pharmaceutical industry faces an uphill task of developing robust analytical, sensitive, and high efficient methods for their determination. ${ }^{2,3}$ Valsartan belongs to the category of antihypertensive drugs that selectively inhibit angiotensin receptor type II. It is used to treat mild-to-moderate essential hypertension. The angiotensinII mediated unwanted effects are reduced to a significant extent by valsartan. Recalls for valsartan were issued between mid-to-late 2018. The cause of the recalls was due to the detection of GTIs such as "N-nitrosodiethylamine (NDEA)" or " $N$-nitrosodimethylamine (NDMA)" in valsartan in unacceptable limits. ${ }^{4}$ The nitrosamine impurities were produced during the drug substance synthesis in which the sodium azide, which is applied in the production of the tetrazole moiety, was eliminated 
using sodium nitrite and later under acidic circumstances would form nitrous acid, a powerful nitrosylating agent. Dimethylamine and diethylamine, which might be present as impurities in dimethylformamide may be $N$-nitrosylated in the synthesis might result in the formation of NDMA and NDEA. Likewise, in certain production processes for valsartan, the reagent triethylamine can degrade to produce diethylamine, and latter $N$-nitrosylated to produce NDEA. $N$-nitroso compounds are included in the "cohort of concern" as they exhibit great carcinogenic potency. 5 ,6 The appropriate regular intake limits for NDEA, NDMA, and other impurities in some products were published by the United States Food and Drug Administration (FDA). The limit of $N$-nitrosoethylisopropylamine (NEIA) and $\mathrm{N}$-nitrosodiisopropylamine (NDIPA) is $96 \mathrm{ng} /$ day.

Recently, for detecting $N$-nitrosamines in water, food, and personal care products, the analytical techniques widely used are gas chromatography (GC), ${ }^{7-18}$ liquid chromatography (LC) $)^{19,20}$ and supercritical fluid chromatography (SFC)-tandem mass spectrometry (MS). ${ }^{21}$ FDA has determined the interim appropriate regular intake levels for $N$-nitrosamines in valsartan (Table 1) and employed GC-MS/MS by using liquid injection and headspace, ${ }^{22,23}$ rapid fire-MS/MS, ${ }^{24}$ and high performance liquid chromatography (HPLC)-high resolution mass spectrometry ${ }^{25}$ for quantification of the $\mathrm{N}$-nitrosamines in valsartan.

In the analysis of water, food, and personal care items, the extraction as well as purification measures are critical and important. However, in the pharmaceutical industry, these were much not much applicable. Liu et al. ${ }^{26}$ reported a GC-MS/MS approach for detecting four "N-nitrosamines" in valsartan, but the method suffers from the drawback of long run time and less accuracy. Therefore, we established through direct injection for quantification of four "N-nitrosamines", as a simple, sensitive, precise, and rapid GC-MS/MS approach for valsartan. The limit of detections (LODs) and limit of quantification (LOQ) values were at acceptable limits as per the sensitivity requirements set by the FDA. The proposed GC-MS/MS approach validation was performed as per the International Council for Harmonization $(\mathrm{ICH})$ guidelines.

\section{MATERIALS AND METHODS}

\section{Chemicals and materials}

Valsartan was found as a gift sample by the local pharma industry. NDMA (purity $\geq 98.3 \%$ ), NDEA (purity $\geq 100.0 \%$ ), NDIPA (purity $\geq 99.9 \%$ ), and NEIA (purity $\geq 99.3 \%$ ) standards were acquired by Sigma Aldrich. The solvents used methanol, acetonitrile, ethyl acetate, 1-methyl-2-pyrrolidinone, which were of all HPLC-grade, were purchased from Merck Ltd.,
Mumbai, India. The structures of valsartan and nitrosamine impurities are presented in Figure 1.

\section{Instrumentation and optimized GC-MS/MS conditions}

Agilent "7890B" "GC-MS/MS" equipped with an "Agilent 7693A" auto sampling device and 7697 a Headspace Sampler was used to examine $\mathrm{N}$-nitrosamines. The analytical column used was DM-WAX (30 m x $0.25 \mathrm{~mm}, 0.5 \mu \mathrm{m})$. This detection was conducted at a $700^{\circ} \mathrm{C}$ triple quadrupole mass spectrometer consisting of electron ionization (EI) ion source. The temperature programming in $\mathrm{GC}$ oven was done by maintaining oven temperature of $70^{\circ} \mathrm{C}$ for $4 \mathrm{~min}$, which first elevated at $20^{\circ} \mathrm{C} \cdot \mathrm{min}^{-1}$ to $240^{\circ} \mathrm{C}$ and maintained for $3 \mathrm{~min}$. The run interval was fixed at $10 \mathrm{~min}$. The flow rate was $3.0 \mathrm{~mL} / \mathrm{min}$ for helium as the carrier gas. The injection temperature as well as injection interface were maintained at $240^{\circ} \mathrm{C}$. The volume of injection in the split mode (1:2) was $1 \mu \mathrm{L}$. MS was run at $70 \mathrm{eV}$ in $\mathrm{El}$ mode with a $150^{\circ} \mathrm{C}$ "quadrupole temperature". The ion source has been adjusted to a temperature of $230^{\circ} \mathrm{C}$. It was $4 \mathrm{~min}$ to delay the solvent. The data recovery mode for the quantitative estimation of "four N-nitrosamine GTIs" was chosen as the "multi-reaction monitoring (MRM)" mode. Table 2 provides a summary of the data for precursor ions, production and enhanced "collision energy" for four $N$-nitrosamine GTIs.

\section{Preparation of samples and standard solutions}

The standard stock solutions of NDMA, NDEA, NEIA, and NDIPA were prepared at $1 \mathrm{mg} / \mathrm{mL}$ concentrations through dissolving weighed reference standards in 1-methyl-2-pyrrolidinone, respectively, and stored at $4^{\circ} \mathrm{C}$. A sequence of standard working

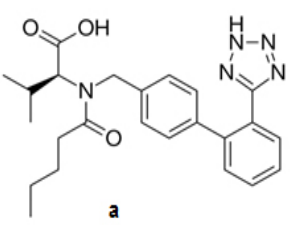<smiles>CN(C)N=O</smiles>

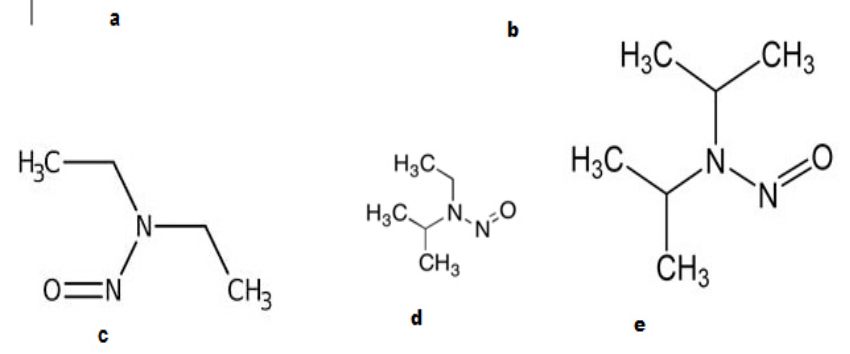

Figure 1. a) Structure of valsartan, b) N-Nitrosodimethylamine, c) N-Nitrosodiethylamine, d) N-Nitrosoethylisopropylamine, e) $\mathrm{N}$-Nitrosodiisopropylamine

\section{Table 1. Interim limits for NDMA and NDEA in valsartan set by FDA}

\begin{tabular}{llllll} 
Drug & $\begin{array}{l}\text { Maximum daily dose } \\
(\mathrm{mg} / \text { day) }\end{array}$ & $\begin{array}{l}\text { Acceptable intake } \\
\text { NDMA (ng/day) }\end{array}$ & $\begin{array}{l}\text { Acceptable intake } \\
\text { NDMA (ppm) }\end{array}$ & $\begin{array}{l}\text { Acceptable intake } \\
\text { NDEA (ng/day) }\end{array}$ & $\begin{array}{l}\text { Acceptable intake } \\
\text { NDEA (ppm) }\end{array}$ \\
\hline Valsartan & 320 & 96 & 0.3 & 26.5 & 0.083 \\
\hline
\end{tabular}

NDMA: $N$-nitrosodimethylamine, NDEA: $N$-nitrosodiethylamine, FDA: United States Food and Drug Administration 
solutions of NDMA at the levels of $0.093,0.155,0.232,0.309$, 0.387 , and $0.464 \mathrm{ppm}(\mu \mathrm{g} / \mathrm{g} \mathrm{API}$ ) in 1-methyl-2-pyrrolidinone was found from a stock solution via the serial dilution process. The sequence of NDEA standard working solution was concentrated at $0.062,0.154,0.231,0.308,0.384$, and $0.461 \mathrm{ppm}$ $(\mu \mathrm{g} / \mathrm{g} \mathrm{API})$, respectively. The working solution concentrations for NEIA were 0.090, 0.150, 0.224,0.299, 0.374, and $0.449 \mathrm{ppm}$ $(\mu \mathrm{g} / \mathrm{g} \mathrm{API})$, respectively. The concentrations of NDIPA were $0.088,0.146,0.220,0.293,0.366$, and $0.439 \mathrm{ppm}(\mu \mathrm{g} / \mathrm{g} \mathrm{API}$ ). Here, $1 \mathrm{ppm}$ corresponds to $0.25 \mu \mathrm{g} / \mathrm{mL}$ of NDMA, NDEA, NEIA, and NDIPA, respectively. At $250 \mathrm{mg} / \mathrm{mL}$ concentration, valsartan was prepared. A mixed standard solution of NDIPA, NEIA, NDEA, and NDMA was prepared from the standard stock solution after subsequent dilution with 1-methyl-2-pyrrolidinone to obtain a concentration within the linearity range. The resulting mixture was sonicated for $30 \mathrm{~min}$ and kept in a centrifuge tube for around $1 \mathrm{~min}$ before being centrifuged for $10 \mathrm{~min}$ at $2500 \mathrm{rpm}$. The supernatant was passed to the chromatography injection vial through the $0.22 \mu \mathrm{m}$ nylon syringe filter.

\section{Method validation}

The developed "GC-MS/MS" approach with MRM mode for detecting four $\mathrm{N}$-nitrosamines was validated for parameters, as solution stability, precision, accuracy, LOQ, LOD, linearity, sensitivity, specificity, and system suitability. For LODs, signalto-noise $(S / N)$ ratio was 3 as well as $L O Q$ s were $S / N$ : 10 . To the accuracy of the proposed method, the recovery studies were conducted for evaluation. The precision studies were evaluated by inter-day and intra-day relative standard deviations (RSDs) of six specimens spiked across 3 continuous days at a single concentration. There was no statistical analysis performed in the developed method.

\section{RESULTS AND DISCUSSION}

\section{Method development}

\section{Selection of solvents}

Considering the trace level of $\mathrm{N}$-nitrosamine GTIs NDMA, NDEA, NEIA, and NDIPA in valsartan and solubility parameter, 1-methyl-2-pyrrolidinone was selected as a solvent for the preparation of solutions for GC-MS/MS analysis.

\section{Capillary column selection}

Under the given temperature program, three different capillary columns were used to obtain the best chromatographic separation. The columns were HP-35MS, HP-5MS, and DMWAX in the order of increasing polarity. A $10 \mu \mathrm{g} / \mathrm{mL}$ normal blend was inserted in all three cases. Identification of the compounds depended on the spectra El using the National Institute of Standards and Technology library. Liu et al. ${ }^{26}$ reported separation of four nitrosamines using DB-WAXetr capillary column without the inclusion of NDEA. We have used the DM-WAX column, which has sufficient polarity to isolate all nitrosamines with better peak shapes, resolution, less analysis time with applicable for the analysis of most polar and volatile compounds, such as NDMA and NDEA.The optimized chromatogram is shown in Figure 2.

\section{Mass spectrometry}

In the analysis of pharmaceuticals, the most crucial aspect is the trace detection method for GTIs. Considering the sensitivity criteria, MRM mode is superior to SIM mode for the quantification of $N$-nitrosamines. Consequently, the MRM mode was used to quantify four $N$-nitrosamine GTI in valsartan as MS approach. MS of valsartan and four $N$-nitrosamine GTIs with chromatograms are shown in Figure 3.

\section{Method validation}

The suggested approach for "four $N$-nitrosamine GTIs" was validated as per $\mathrm{ICH}$ recommendations.

\section{Specificity}

For the specificity of the recommended approach, 1-methyl2-pyrrolidinone, the valsartan matrices and mixed standards of four $N$-nitrosamines were undergone by the "GC-MS/MS" examination. At the retention times of four $N$-nitrosamines there is no interference peaks from the 1-methyl-2-pyrrolidinone, and the valsartan matrices were observed, indicating the specificity of the approach for detecting four $N$-nitrosamines in valsartan.

\section{Sample Chromatogram}

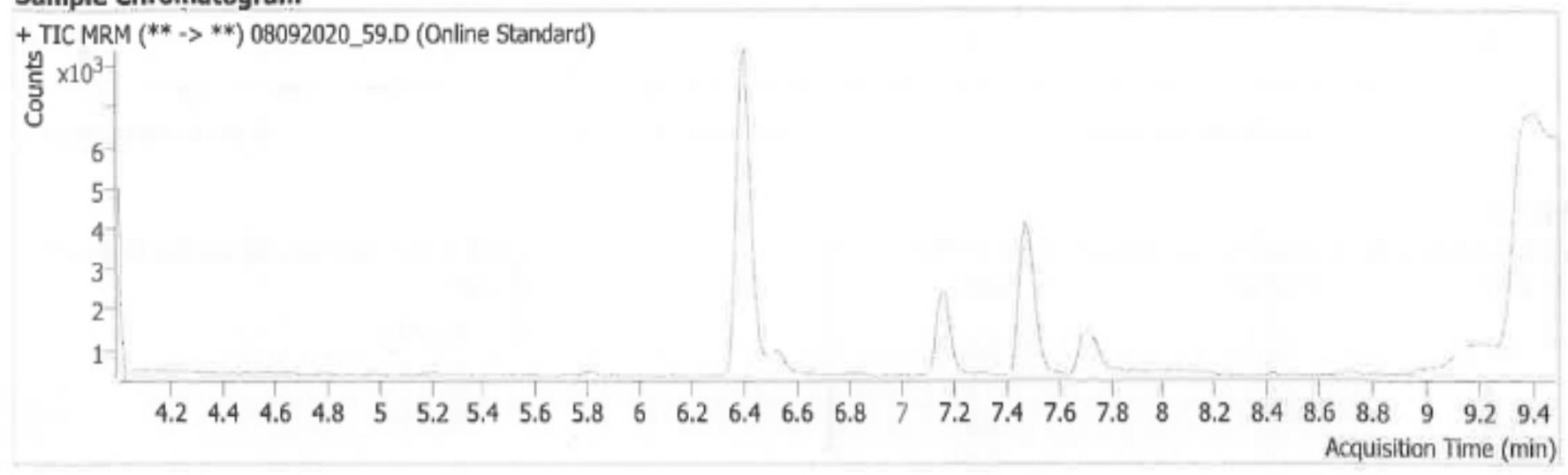

Figure 2. GC chromatograms of mixed standard solution of $\mathrm{N}$-nitrosamines

GC: Gas chromatography 

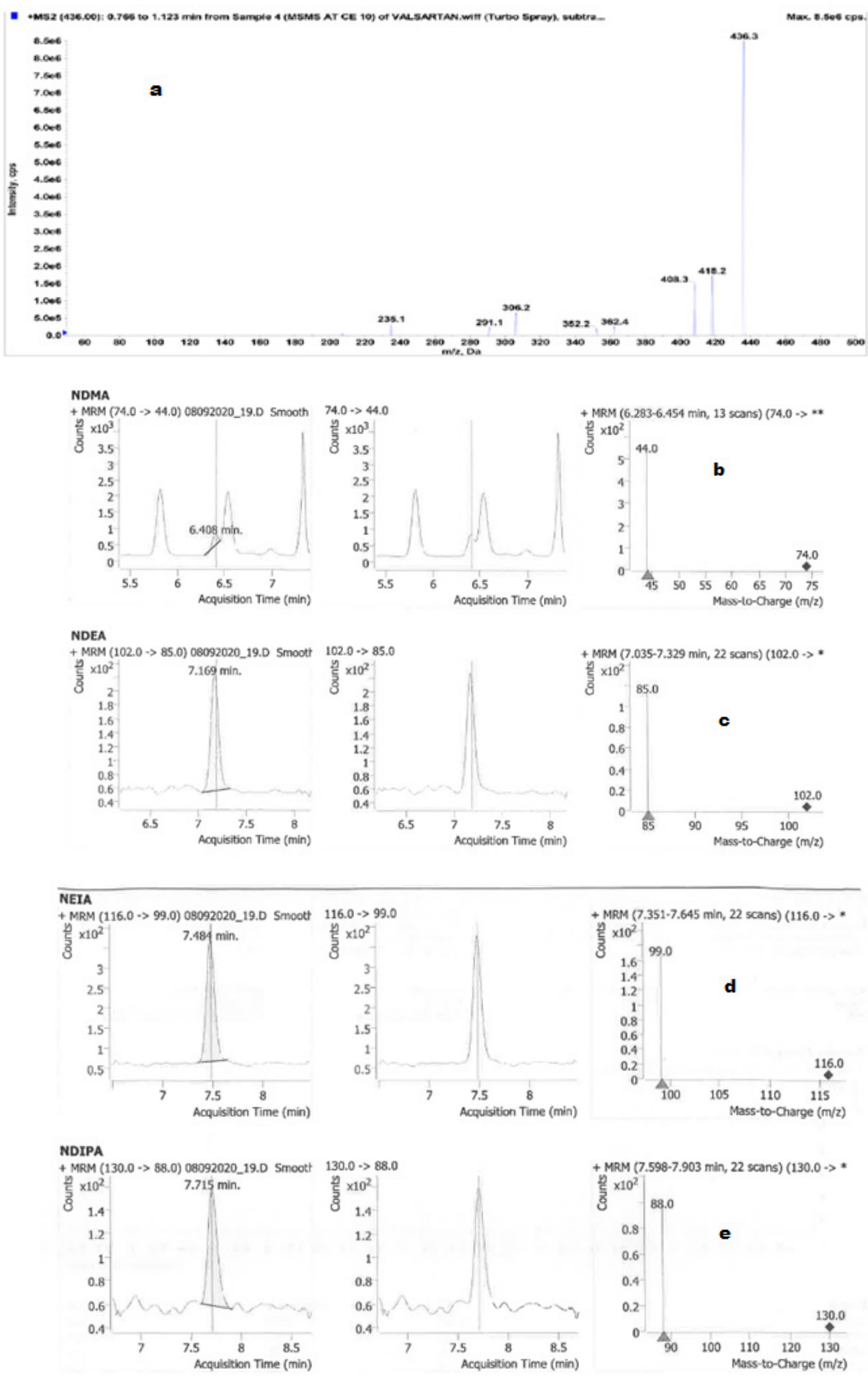

Figure 3. a) Mass spectra of valsartan, b) $\mathrm{N}$-nitrosodimethylamine, c) $\mathrm{N}$-nitrosodiethylamine, d) $\mathrm{N}$-nitrosoethylisopropylamine, e) $N$-nitrosodiisopropylamine 


\section{Linearity and sensitivity}

The data for linearity, LOQ, and LOD outcomes are summarized in Table 3. The standard curve $(y=A x+B$, in which $A$ signifies the slope and $B$ signifies the intercept) was obtained by plotting the chromatographic peak area (N-nitrosamines, y) to normal $N$-nitrosamines ( $x$ ) concentrations. To validate the linearity of the approach, six standard concentrations were used. The regression coefficients $\left(R^{2}\right)$ of the standard curve for four $\mathrm{N}$-nitrosamines were $>0.99$ in the given concentration range, indicating better linearity and is appropriate for the quantitative examination, as shown in Figure 4. Therefore, based on LODs and LOQs, the sensitivity of the method was evaluated. In Table 3, LODs and LOQs for NDEA, NEIA, NDIPA, and NDMA in 1-methyl-2-pyrrolidinone are presented. The low values of LOQs and LODs for this GC-MS/MS approach were acceptable and suitable for detecting $N$-nitrosamines in valsartan.

\section{Accuracy}

The accuracy of the method was estimated from the recovery results of four $N$-nitrosamines. To evaluate the output of the recommended approach, improvements of four $N$-nitrosamines were determined after valsartan samples spiked with 3 separate levels of four $N$-nitrosamines at 50\% (NDIPA-0.146 ppm, NDEA-0.154 ppm, NDMA-0.155 ppm, NEIA-0.150 ppm), 100\% (NDIPA-0.293 ppm, NDEA-0.308 ppm ,NDMA-0.309 ppm, NEIA-0.299 ppm), and 150\% (NDIPA-0.439 ppm, NDEA0.461 ppm, NDMA-0.464 ppm, NEIA-0.449 ppm) of the limits, respectively. The recoveries for NDIPA, NDEA, NDMA, and NEIA in valsartan were in the range of 87.68 to $122.75 \%$, as shown in Table 4. Considering the ultra-trace essence of the study, the recovery of $\mathrm{N}$-nitrosamines was found in the acceptable range of $70-130 \%$, indicating the accuracy of the proposed method for $N$-nitrosamines.

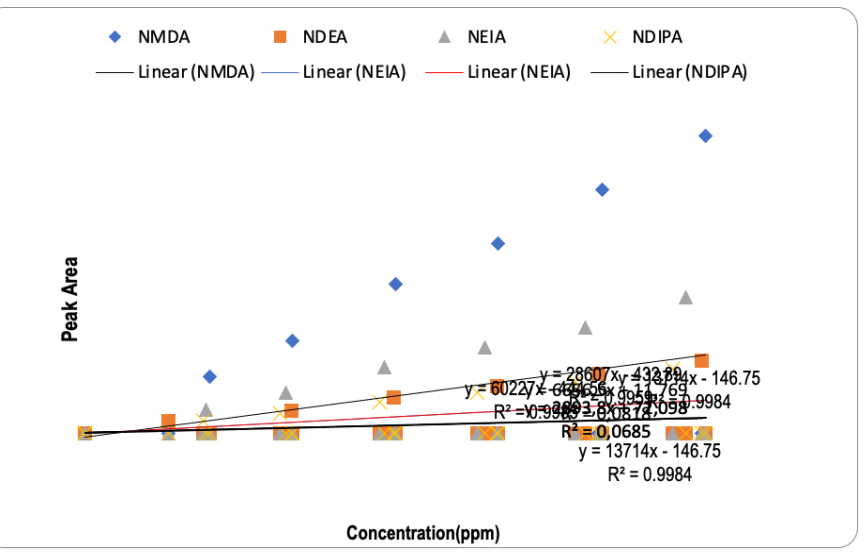

Figure 4. Calibration curve of four $\mathrm{N}$-nitrosamines

Table 2. Multiple reactions monitoring transitions and optimized collision energy for four $N$-nitrosamine GTIs

\begin{tabular}{llll} 
Analyte & Precursor $\rightarrow$ product $(\mathrm{m} / z)$ & Dwell time $(\mathrm{ms})$ & Collision energy (eV ) \\
\hline$N$-nitrosodimethylamine & $74 \rightarrow 44$ & 200 & 5 \\
\hline$N$-nitrosodiethylamine & $102 \rightarrow 85$ & 200 & 5 \\
\hline$N$-nitrosoethylisopropylamine & $116 \rightarrow 99$ & 200 & 5 \\
\hline$N$-nitrosodiisopropylamine & $130 \rightarrow 88$ & 200 & 5 \\
\hline
\end{tabular}

GTIs: Genotoxic impurities

Table 3. Calibration curves, LODs, and LOQs for four $N$-nitrosamines

\begin{tabular}{llllll} 
Analyte & Linearity range $(\mathrm{ppm})$ & Regression equation & $\mathrm{R}^{2}$ & LOD (ppm) & LOQ (ppm) \\
\hline$N$-nitrosodimethylamine & $0.093-0.464$ & $\mathrm{Y}=60227 \mathrm{X}-444.56$ & 0.9985 & 0.03 & 0.09 \\
\hline$N$-nitrosodiethylamine & $0.062-0.461$ & $\mathrm{Y}=13714 \mathrm{X}-146.75$ & 0.9984 & 0.02 & 0.06 \\
\hline$N$-nitrosoethylisopropylamine & $0.09-0.449$ & $\mathrm{Y}=28067 \mathrm{X}-432.89$ & 0.9959 & 0.03 & 0.09 \\
\hline$N$-nitrosodiisopropylamine & $0.088-0.439$ & $\mathrm{Y}=13714 \mathrm{X}-146.75$ & 0.9984 & 0.03 & 0.09 \\
\hline
\end{tabular}

LODs: Limit of detections, LOQs: Limit of quantification, $\mathrm{R}^{2}$ : Regression coefficients

Table 4. Accuracy data of four nitrosoamines

\begin{tabular}{|c|c|c|c|c|}
\hline Analyte & $\begin{array}{l}\text { Valsartan concentration } \\
(\mathrm{mg} / \mathrm{mL})\end{array}$ & $\begin{array}{l}\text { Mean \% recovery at } \\
50 \% \text { level } \pm \text { SD }\end{array}$ & $\begin{array}{l}\text { Mean } \% \text { recovery at } 100 \% \\
\text { level } \pm \text { SD }\end{array}$ & $\begin{array}{l}\text { Mean \% recovery at } 150 \\
\% \text { level } \pm \text { SD }\end{array}$ \\
\hline $\mathrm{N}$-nitrosodimethylamine & \multirow{3}{*}{250} & $103.21 \pm 0.23$ & $101.15 \pm 0.98$ & $102.29 \pm 1.89$ \\
\hline$N$-nitrosoethylisopropylamine & & $114.42 \pm 0.31$ & $112.21 \pm 1.38$ & $117.83 \pm 1.66$ \\
\hline $\mathrm{N}$-nitrosodiisopropylamine & & $111.41 \pm 1.73$ & $113.62 \pm 0.99$ & $122.75 \pm 0.26$ \\
\hline
\end{tabular}

SD: Standard deviation 
Table 5. Precision results of four nitrosoamines

\begin{tabular}{|c|c|c|c|c|c|c|c|}
\hline \multirow[t]{2}{*}{ Drug (API) } & \multirow[t]{2}{*}{ Analyte } & \multirow{2}{*}{$\begin{array}{l}\text { Concentration } \\
(\mathrm{ppm})^{\star} \\
(\mu \mathrm{g} / \mathrm{g} \text { API) }\end{array}$} & \multirow{2}{*}{$\begin{array}{l}\text { System } \\
\text { precision } \\
\text { (RSD \%) }\end{array}$} & \multicolumn{2}{|c|}{$\begin{array}{l}\text { Method precision (RSD } \\
\%)\end{array}$} & \multicolumn{2}{|c|}{$\begin{array}{l}\text { Intermediate precision } \\
\text { (RSD \%) }\end{array}$} \\
\hline & & & & Interday & Intraday & Analyst I & Analyst II \\
\hline \multirow{2}{*}{ Valsartan } & $\mathrm{N}$-nitrosodimethylamine & 0.309 & 6.43 & 1.44 & 1.37 & 2.53 & 2.74 \\
\hline & $N$-nitrosodiethylamine & 0.308 & 8.52 & 3.46 & 3.83 & 4.28 & 3.83 \\
\hline \multirow[t]{2}{*}{$(250 \mathrm{mg} / \mathrm{mL})$} & $N$-nitrosoethylisopropylamine & 0.299 & 7.02 & 2.26 & 2.69 & 6.35 & 5.97 \\
\hline & $N$-nitrosodiisopropylamine & 0.293 & 9.21 & 2.79 & 2.93 & 6.41 & 7.27 \\
\hline
\end{tabular}

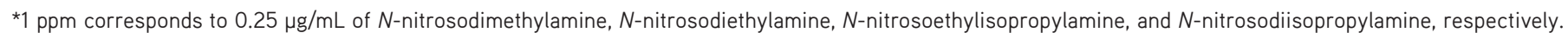
API: Active pharmaceutical ingredient, RSD: Relative standard deviation

\section{Precision}

To study the method precision, the inter-day and intra-day accuracy tests were performed. The intra-day precision measurements were carried out by comparison of the "SD" of the recovery proportions of the spiked specimens analyzed on the same day. For inter-day accuracy, spiked samples were tested for three distinct days. The intermediate precision was evaluated by results from the study on a different day with different analysts and with freshly prepared solutions. As reviewed in Table 5, this GC-MS/MS approach demonstrated acceptable percentage RSD values for the inter-day, intra-day precision as well as intermediate accuracy was between 1.45$6.38 \%, 2.88-9.15 \%$, and $2.8-3.7 \%$, respectively.

\section{Stabilities of four N-nitrosamines in 1-methyl-2-pyrrolidinone}

To study four $N$-nitrosamines solution stabilities in 1-methyl2-pyrrolidinone, $0.3 \mathrm{ppm}$ standard solutions were prepared and analyzed every $4 \mathrm{~h}$ for a recently prepared standard. Each solution was placed at $25^{\circ} \mathrm{C}$ in the dark. The recovery percentage of $\mathrm{N}$-nitrosamines from these stock solutions was between 97.51 and $105.04 \%$, and the differential recoveries of $\mathrm{N}$-nitrosamines at $\mathrm{O} \mathrm{h}$ and $24 \mathrm{~h}$ at just $10 \%$, indicate the stability of the stock solution for at least $24 \mathrm{~h}$.

\section{Applications in samples}

This GC-MS/MS process was used in the determination of four $N$-nitrosamine GTIs in four batches of commercial valsartancontaining products and none of the four " $N$-nitrosamines" were observed in four batches of the commercially available formulation.

\section{CONCLUSION}

A simple and sensitive MRM mode-based GC-MS/MS approach was created for estimating four GTIs i.e. NEIA, NDIPA, NDEA, and NDMA in valsartan. The reported GC-MS/MS approach demonstrates satisfactory sensitivity and selectivity. The run time was under $10 \mathrm{~min}$. The results of four $N$-nitrosamines in LOQs and LODs ranged 0.06-0.09 ppm and 0.02-0.03 ppm correspondingly, indicating the suitability of four $N$-nitrosamines in valsartan for sensitive quantification.

Ethics

Ethics Committee Approval: Not required.
Informed Consent: Not applicable as our study does not involve any human volunteers and animals.

Peer-review: Externally peer-reviewed.

\section{Authorship Contributions}

Concept: S.R.T., Design: S.R.T., K.P.A., Data Collection or Processing: S.R.T., Analysis or Interpretation: S.R.T., K.P.A., Literature Search: K.P.A., Writing: K.P.A.

Conflict of Interest: No conflict of interest was declared by the authors.

Financial Disclosure: The authors declared that this study received no financial support.

\section{REFERENCES}

1. Szekely G, Amores de Sousa MC, Gil M, Castelo Ferreira F, Heggie W. Genotoxic impurities in pharmaceutical manufacturing: sources, regulations, and mitigation. Chem Rev. 2015;115:8182-8229.

2. Raman NV, Prasad AV, Ratnakar Reddy K. Strategies for the identification, control and determination of genotoxic impurities in drug substances: a pharmaceutical industry perspective. J Pharm Biomed Anal. 2011;55:662-667.

3. Teasdale A, Elder DP. Analytical control strategies for mutagenic impurities: current challenges and future opportunities? Trends Anal Chem. 2014;103:2-28.

4. Scherf-Clavel O, Kinzig M, Besa A, Schreiber A, Bidmon C, Abdel-Tawab M, Wohlfart J, Sörgel F, Holzgrabe U. The contamination of valsartan and other sartans, part 2: untargeted screening reveals contamination with amides additionally to known nitrosamine impurities. J Pharm Biomed Anal. 2019;172:278-284.

5. Buist HE, Devito S, Goldbohm RA, Stierum RH, Venhorst J, Kroese ED. Hazard assessment of nitrosamine and nitramine by-products of amine-based CCS: alternative approaches. Regul Toxicol Pharmacol. 2015;71:601-623.

6. Ravnum S, Rundén-Pran E, Fjellsbø LM, Dusinska M. Human health risk assessment of nitrosamines and nitramines for potential application in $\mathrm{CO}_{2}$ capture. Regul Toxicol Pharmacol. 2014;69:250-255.

7. Chen W, Li X, Huang H, Zhu X, Jiang X, Zhang Y, Cen K, Zhao L, Liu X, Qi S. Comparison of gas chromatography-mass spectrometry and gas chromatography-tandem mass spectrometry with electron ionization for determination of $\mathrm{N}$-nitrosamines in environmental water. Chemosphere. 2017;168:1400-1410. 
8. Hong $\mathrm{Y}$, Kim KH, Sang BI, Kim H. Simple quantification method for $\mathrm{N}$-nitrosamines in atmospheric particulates based on facile pretreatment and GC-MS/MS. Environ Pollut. 2017;226:324-334.

9. Luo YB, Chen XJ, Zhang HF, Jiang XY, Li X, Li XY, Zhu FP, Pang YQ, Hou HW. Simultaneous determination of polycyclic aromatic hydrocarbons and tobacco-specific $\mathrm{N}$-nitrosamines in mainstream cigarette smoke using in-pipette-tip solid-phase extraction and on-line gel permeation chromatography-gas chromatography-tandem mass spectrometry. J Chromatogr A. 2016;1460:16-23.

10. McDonald JA, Harden NB, Nghiem LD, Khan SJ. Analysis of $\mathrm{N}$-nitrosamines in water by isotope dilution gas chromatographyelectron ionisation tandem mass spectrometry. Talanta. 2012;99:146-154.

11. Scheeren MB, Sabik H, Gariépy C, Terra NN, Arul J. Determination of $\mathrm{N}$-nitrosamines in processed meats by liquid extraction combined with gas chromatography-methanol chemical ionisation/mass spectrometry. Food Addit Contam Part A Chem Anal Control Expo Risk Assess. 2015;32:1436-1447.

12. Sieira BJ, Carpinteiro I, Rodil R, Quintana JB, Cela R. Determination of $\mathrm{N}$-nitrosamines by gas chromatography coupled to quadrupole-time-offlight mass spectrometry in water samples. Separations. 2020;7:3.

13. Zhu M, Ye Q, Zhou T, Chen L, Yu L, Li B, Hu J, Zhou M. [Determination of 10 volatile $\mathrm{N}$-nitrosamines in meat products by gas chromatographytandem mass spectrometry]. Se Pu. 2019;37:207-215.

14. Hung HW, Lin TF, Chiu CH, Chang YC, Hsieh TY. Trace analysis of $\mathrm{N}$-nitrosamines in water using solid-phase microextraction coupled with gas chromatograph-tandem mass spectrometry. Water Air Soil Pollut. 2010;213:459-469.

15. Pozzi R, Bocchini P, Pinelli F, Galletti GC. Determination of nitrosamines in water by gas chromatography/chemical ionization/selective ion trapping mass spectrometry. J Chromatogr A. 2011;1218:1808-1814.

16. Yoon $S$, Nakada N, Tanaka H. A new method for quantifying $N$-nitrosamines in wastewater samples by gas chromatography-triple quadrupole mass spectrometry. Talanta. 2012;97:256-261.

17. Wang Z, Zhai M, Xia X, Yang M, Han T, Huang M. A simple method for monitoring eight $N$-nitrosamines in Beef Jerkys by gas chromatographytandem mass spectrometry with one-step treatment coupled to active carbon solid-phase extraction. Food Anal Methods. 2018;11:933-938.
18. Ma Q, Xi HW, Wang C, Bai H, Xi GC, Su N, Xu LY, Wang JB. Determination of ten volatile nitrosamines in cosmetics by gas chromatography tandem mass spectrometry. Chinese J Anal Chem. 2011;39:1201-1207.

19. Herrmann SS, Duedahl-Olesen L, Granby K. Simultaneous determination of volatile and non-volatile nitrosamines in processed meat products by liquid chromatography tandem mass spectrometry using atmospheric pressure chemical ionisation and electrospray ionisation. J Chromatogr A. $2014 ; 1330: 20-29$.

20. Ngongang $A D$, Duy SV, Sauvé S. Analysis of nine $N$-nitrosamines using liquid chromatography-accurate mass high resolution-mass spectrometry on a Q-exactive instrument. Anal Methods. 2015;7:57485759.

21. Schmidtsdorff S, Schmidt AH. Simultaneous detection of nitrosamines and other sartan-related impurities in active pharmaceutical ingredients by supercritical fluid chromatography. J Pharm Biomed Anal. 2019;174:151-160.

22. U.S. Food \& Drug Administration (FDA). Combined direct injection nnitrosodimethylamine (NDMA), $N$-nitrosodiethylamine (NDEA), $N$-nitrosoethylisopropylamine (NEIPA), $\quad N$-nitrosodiisopropylamine (NDIPA), and $\mathrm{N}$-nitrosodibutylamine (NDBA) impurity assay by GC-MS/ MS. 2019.

23. U.S. Food \& Drug Administration (FDA). Combined headspace $\mathrm{N}$-nitrosodimethylamine (NDMA), $\mathrm{N}$-nitrosodiethylamine (NDEA), $\mathrm{N}$-nitrosoethylisopropylamine (NEIPA), and $\mathrm{N}$-nitrosodiisopropylamine (NDIPA) impurity assay by GC-MS/MS. 2019.

24. U.S. Food \& Drug Administration (FDA). Development and validation of a RapidFire-MS/MS method for screening of nitrosamine carcinogen impurities $N$-nitrosodimethylamine (NDMA), $\mathrm{N}$-nitrosodiethylamine (NDEA), $\mathrm{N}$-nitrosoethylisopropylamine (NEIPA), $\mathrm{N}$-nitrosodiisopropylamine (NDIPA), $\mathrm{N}$-nitrosodibutylamine (NDBA) and $\mathrm{N}$-nitroso-N-methyl-4-aminobutyric acid (NMBA) in ARB drugs. 2019.

25. U.S. Food \& Drug Administration (FDA). Liquid chromatography-high resolution mass spectrometry (LC-HRMS) method for the determination of six nitrosamine impurities in ARB drugs. 2019.

26. Liu J, Xie B, Mai B, Cai Q, He R, Guo D, Zhang Z, Fan J, Zhang W. Development of a sensitive and stable GC-MS/MS method for simultaneous determination of four $\mathrm{N}$-nitrosamine genotoxic impurities in sartan substances. J Anal Sci Technol. 2021;12:1-8. 